\title{
Assessment of Copper and Iron Concentration in Water of Yamuna River, Delhi, India
}

\author{
Kapil Parihar $^{1(\mathbb{D})}$, Mahipal Singh Sankhla ${ }^{1, * \mathbb{D}}$, Rajeev Kumar ${ }^{1 \mathbb{( D}}$, Anubhav Singh ${ }^{2}$ (D) \\ 1 Department of Forensic Science, School of Basic and Applied Sciences, Galgotias University, Greater Noida, India; \\ kparihar94@gmail.com (K.P.); mahipal4n6@gmail.com (M.S.S.); rajeev4n6@gmail.com (R.K.); \\ 2 Department of Forensic Science, School of Basic and Applied Sciences, Galgotias University, Greater Noida, India; \\ as1951026@gmail.com (A.S.); \\ * Correspondence: mahipal4n6@gmail.com;
}

Received: 20.10.2020; Revised: 14.11.2020; Accepted: 17.11.2020; Published: 21.11.2020

\begin{abstract}
The concentration of Copper $(\mathrm{Cu})$ and Iron $(\mathrm{Fe})$ in water from River Yamuna, Delhi, India, were determined by Inductively Coupled Plasma Mass Spectrometry (ICP-MS). Heavy metals are potentially toxic and are transferred to the surrounding environment through different pathways. Heavy metals are considered one of the most dangerous groups since they are non-degradable due to their persistent nature, toxicity, and tendency to accumulate in organisms and alters the food chain cycle and still more. Yamuna river water may become contaminated by the accumulation of trace metals and metalloids through emissions from the rapidly expanding industrial areas, disposal of high metal wastes, leaded gasoline and paints, land application of fertilizers, animal manures, sewage sludge, pesticides, wastewater irrigation, and Electronic waste. Trace element toxicity has proven to be a major threat, and there are several health risks associated with it. Even though they do not have any biological role, these metals' toxic effects remain present in some of the other forms harmful for the human body and its proper functioning. On comparison of these heavy metals concentration in water, it was found that $\mathrm{Fe}$, $\mathrm{Cu}$ were higher than the permissible limits of WHO, which gives an indication of hazardous risk to human health.
\end{abstract}

Keywords: water; trace element; Yamuna River; hazardous.

(C) 2020 by the authors. This article is an open-access article distributed under the terms and conditions of the Creative Commons Attribution (CC BY) license (https://creativecommons.org/licenses/by/4.0/).

\section{Introduction}

Water is most abundantly available on Earth and required by all kinds of life. Adequate qualitative and quantitative water supply is essential for small as well as big cities and towns. The quality of water is of vital concern for humanity since it is directly linked with human welfare. India is a country that has a rich and vast history of social and economic prosperity and environmental richness. Rivers (Goddesses in Indian Culture) have been facing the curse of pollution for a long time because of unplanned development, urbanization, industrialization, population density, and agricultural activities [1]. The River Yamuna is the largest tributary of River Ganga. This river is as prominent and sacred as the great River Ganga itself. It has been acclaimed as a holy river in Indian mythology. Various pilgrimage centers, e.g., Yamunotri (Uttaranchal), Paonta Sahib (Himachal Pradesh), Mathura, Vrindavan, Bateshwar \& Allahabad (all in Uttar Pradesh) are located at the banks of this river. Large urban centers, e.g., Yamuna Nagar, Sonepat, Delhi, India's political nucleus, Gautam Budh Nagar, Faridabad, Mathura, Agra, and Etawah, are also established on its banks. Large industrial centers have also been developed either on banks or in its basin. On the agriculture front, the Yamuna basin is one of 
the highly fertile and high food grain yielding basins, especially in Haryana and the Western district in Uttar Pradesh.

All this reflects that the River Yamuna flows in the hearts of Indians and plays a significant role in the country's economy. This river Yamuna is also influenced by industrialization, urbanization, and rapid agricultural developments similar to other riverine systems [2]. Therefore, the river water is being utilized for fishing, aquaculture, irrigation, and domestic purposes, river basin to cultivate vegetables and cereals. These activities are indispensable for the nutritional requirement and uplift of millions of households [3]. There is a huge adverse effect on health depending upon the amount of consumption of Heavy metal [4]. The concentration of Heavy metal in vegetables, plants, water bodies \& etc. Human health is directly affected by polluted water, fish, fruits, vegetables, plants, etc. These are the primary sources of food for humans [5-9]. These pollutants, heavy metals found one of the most hazardous since their stubborn nature, tendency, toxicity to accrue in organisms, and undergo food chain increase, and more still, they are non-degradable. Heavy metal can cause extensive toxicity in humans, such as cardiovascular damage, gastrointestinal tract and central nervous system, and various organs in the body like liver, kidney, lungs \& etc. It is not probable to entirely avoid contact with toxic metals[10-16]. The effect of human exposure to mixtures of heavy metals is presently a significant research area in neurotoxicology. With this background, the collected water samples were from the Yamuna River to evaluate the degree of contamination and biomagnifications [17-21]. This research study aimed to assess the Iron \& copper contamination due to the sewage aquatic ecosystem and information to understand better the environmental impact of the trace element that contaminates the river and aquatic life. This information would be a useful tool for effective management and control of the natural recourses.s

\section{Materials and Methods}

\subsection{Sampling duration.}

Samples of Water from the 5 Sampling Site of water was done at the Yamuna River. Sampling was collected during the 15-15 days from 4 Months from January to April 2019.

\subsection{Sample preparation.}

All water specimens were brought to the lab, where they sieved through Whatman No.41 ( $0.45 \mu \mathrm{m}$ pore size) filter paper. The specimens were acidified with $2 \mathrm{ml}$ concentrated Nitric acid to prevent precipitation of Chromium, decrease adsorption of the analyses onto the walls of containers, and to avoid microbial activity; then, water samples were stored at $4{ }^{\circ} \mathrm{C}$ until the analysis [22].

\subsection{Instrumentation.}

The concentrations of heavy metals were determined in all samples by Inductively Coupled Plasma Mass Spectrometry (ICP-MS). It is a standard laboratory analytical tool for metal analysis. 


\section{Results and Discussion}

The Concentration of Iron, Copper, and Arsenic in Water every 15 days throughout 4 months from January to April 2019, was detected and compared with the permissible limits as set by the World Health Organization. The concentration of Iron \& Copper in all Water samples at all five different Sites of Yamuna River, the concentration of Iron \& Copper in all Water samples was detected in the cold season and Springer seasons. The results are discussed below. The data was analyzed through $\mathrm{R}$ studio.

\subsection{The concentration of copper in water in different months.}

In January, the concentration of copper in water is 3.579 and 4.968. In February, the concentration of copper in water is 4.066 and 4.261. In March, the concentration of copper in water is 3.934 and 3.838. In April, the concentration of copper in water is 5.108 and 4.519. The WHO guidelines for the maximum permissible limit of copper is $2 \mathrm{ppm}$. As the copper range is higher than the permissible limit, it may cause severe toxicity of copper in human beings and animals.

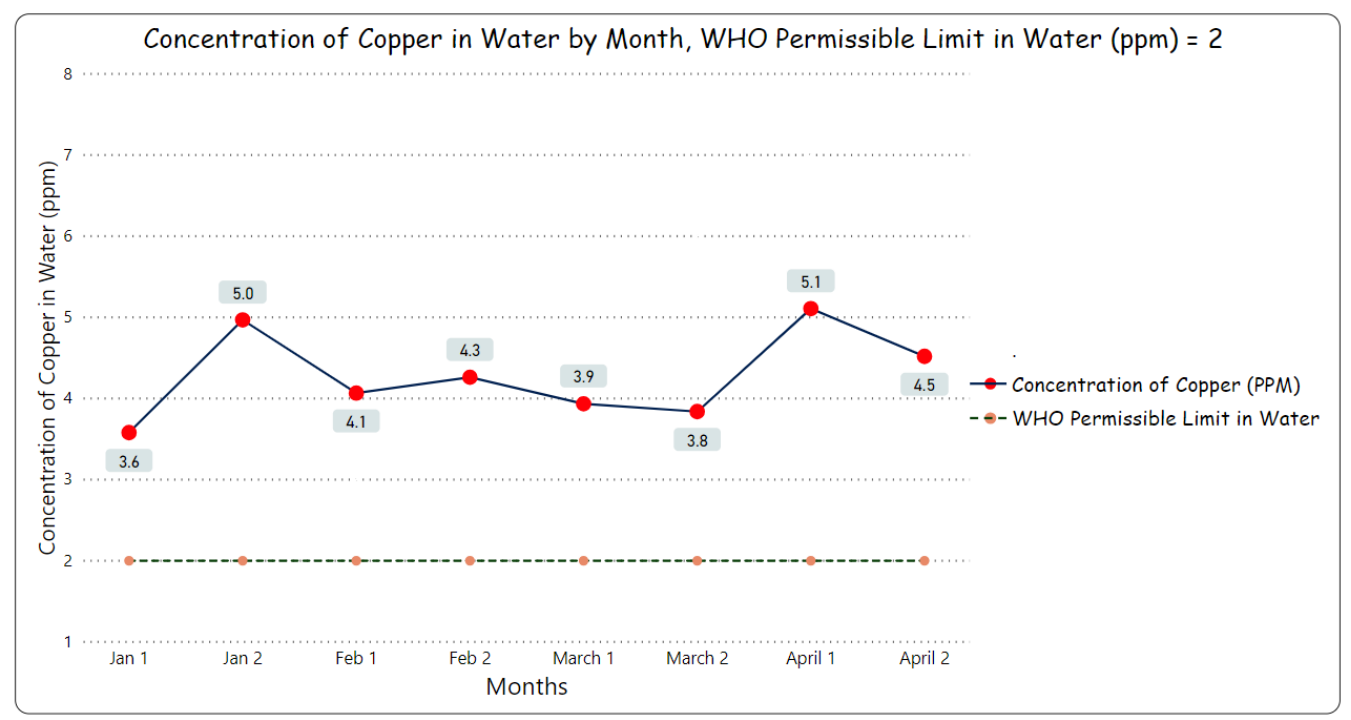

Figure 1. Concentration of copper in water in a different month.

\subsection{The concentration of copper in water in different sites.}

On-site of January 1, the concentration of copper in water is site1-3.2, site2-2.9, site34.3, site4-3.5, site5-4.0, and January 2, the concentration of copper in water is site1-5.2, site24.3, site3-6.5, site4-5.3, site5-3.5. In February 1, the concentration of copper in water is site13.0, site2-4.1, site3-3.8, site4-4.3, site5-5.1, and February 2 the concentration of copper in water is site1-3.5, site2-5.9, site3-3.6, site4-4.0, site5-4.3. On March 1, the concentration of copper in water is site1-3., site2-4.1, site3-3.8, site4-5.3, site5-3.5, and on March 2, the copper concentration in water is site1-4.6, site2-3.7, site3-4.3, site4-3.5, site5-3.1. In April 1, the concentration of copper in water is site1-6.0, site2-4.9, site3-4.6, site4-5.8, site5-4.4, and April 2 , the concentration of copper in water is site1-3.5, site2-4.7, site3-3.2, site4-5.5, site5-5.6. The WHO guidelines for the maximum permissible limit of copper is $2 \mathrm{ppm}$. As the range of copper is higher than the permissible limit, it may cause severe toxicity of copper in human beings and animals. 


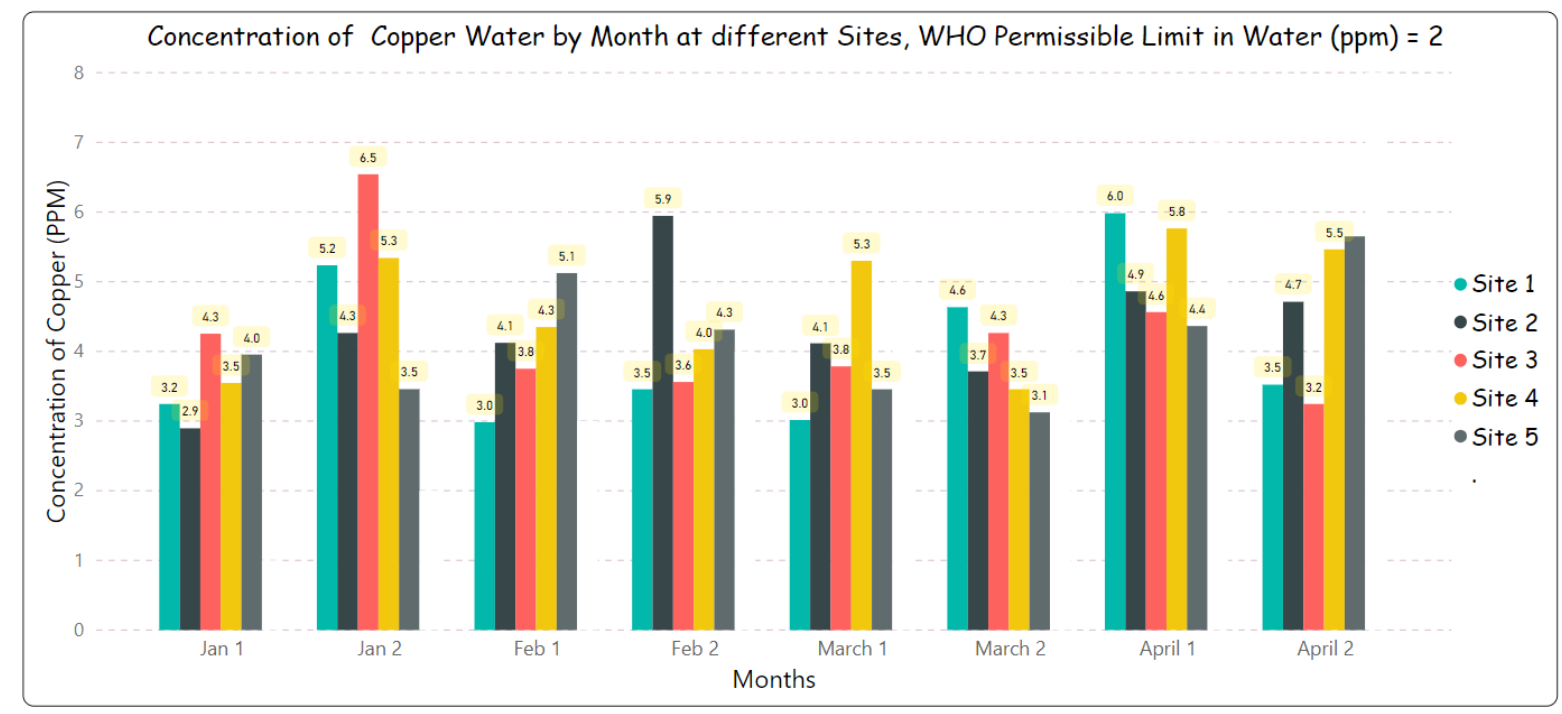

Figure 2. Concentration of copper in water in a different site.

\subsection{The concentration of iron in water in a different month.}

In January, the concentration of iron in water is 1.893 and 1.078. In February, the concentration of iron in water is 1.427 and 1.831. In March, the concentration of iron in water is 2.578 and 2.690. In April, the concentration of iron in water is 2.733 and 2.694. The WHO guidelines for the maximum permissible limit of iron is $1.00 \mathrm{ppm}$. As the iron range is higher than the permissible limit, it may cause severe toxicity of iron in human beings and animals.

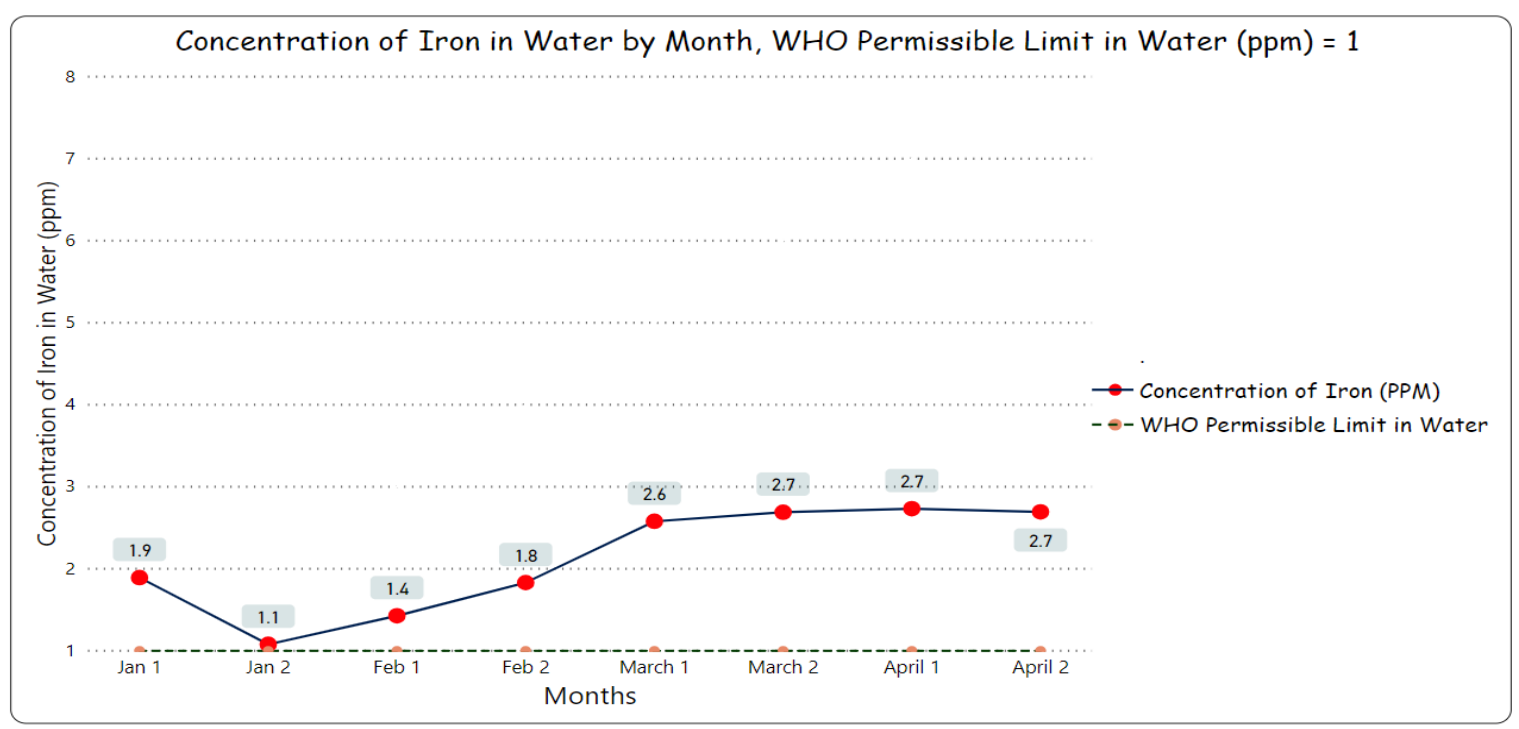

Figure 3. Concentration of iron in water in a different month.

\subsection{The concentration of iron in water in a different site.}

In site of January 1 the concentration of iron in water is site1-2.6, site2-1.4, site3-0.2, site4-1.4, site5-3.8 and January 2 the concentration of iron in water is site1-0.1, site2-1.0, site30.9, site4-2.2, site5-1.1. In month of February 1 the concentration of iron in water is site1-1.9, site2-1.8, site3-0.2, site4-3.2, site5-0.1 and February 2 the concentration of iron in water is site1-2.1, site2-2.0, site3-1.1, site4-1.6, site5-2.3. In month of March 1 the concentration of iron in water is site1-2.4, site2-2.1, site3-2.9, site4-2.7, site5-3.7, and March 2 the concentration of iron in water is site1-2.4, site2-1.2, site3-2.8, site4-3.9, site5-3.1. In month of April 1 the 
concentration of iron in water is site1-3.0, site2-1.9, site3-2.1, site4-3.4, site5-3.3 and April 2 the concentration of iron in water is site1-2.2, site2-2.2, site3-3.2, site4-2.2, site5-3.6. The WHO guidelines for the maximum permissible limit of iron is $1 \mathrm{ppm}$. As the range of iron is higher than the permissible limit, it may cause severe toxicity of iron in human beings and animals.

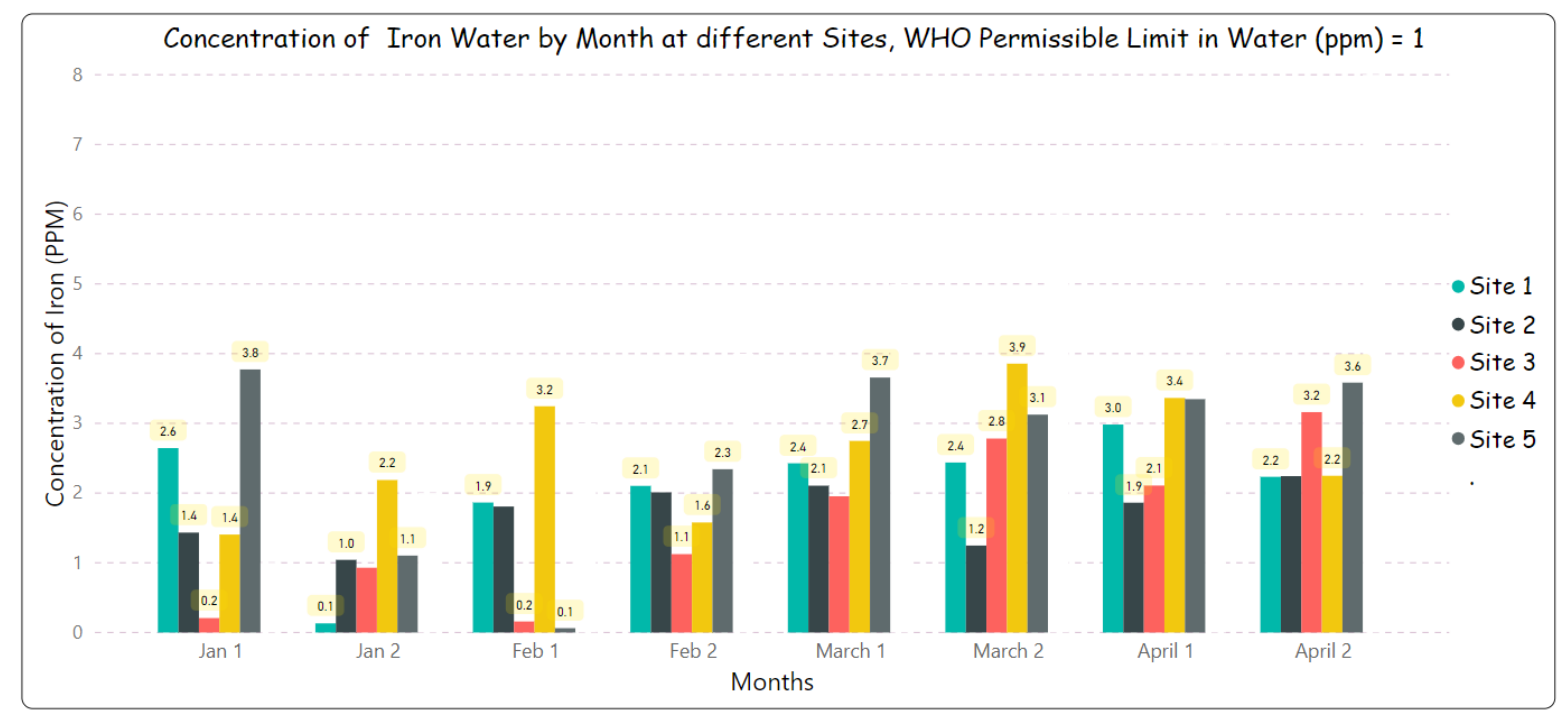

Figure 4. Concentration of iron in water in a different site.

\section{Conclusions}

This research study was the Yamuna River, Delhi Area water samples are analyzed. They contain Heavy metal concentration more than the acceptable and desirable levels WHO except arsenic are found below the permissible limit of WHO. Most of the water samples were highly contaminated, which is not possible for drinking purposes. The toxicologist has continually detected the heavy metal concentration in various water bodies. The rise in elemental pollution makes water and fish unsuitable for consumption, causing severe health problems. The concentration of heavy metals has already crossed or is at the borderline of the permissible limit as declared by the World Health Organization. However, the data suggests that somewhere the elemental concentrations are still below the permissible limit. Human health is directly affected by polluted water, Sediment, fishes, fruits, vegetables, plants, etc. Studies show that Industrial wastes, E-waste, Sewage, Natural source, anthropogenic source, and Agricultural activities that have released hazardous and toxic constituents in the Yamuna River water led to contamination of drinking water in these areas. Diseases like Neurotoxicity, Carcinogenicity is related to contamination of water and Sediment with heavy metals such as Copper $(\mathrm{Cu})$, Iron $(\mathrm{Fe})$. The practice of trace element detection should be continued to lower the possible consumption of contaminated eatables. People should be beware of the hazardous effects of the consumption of polluted water and eatables. It is recommended that awareness be spread among the people regarding the hazards of polluted water and contaminated eatables. It is also essential that farmers be educated to reduce such contamination and be encouraged to use a controlled amount of pesticides to avoid wastewater leaching. Cultivation of fields should be practiced far away from the industrial area and areas prone to contamination. The WHO has recommended it. The bioaccumulation of Heavy metals may pose a significant hazard to humans and animals' health that rely on water bodies. Technologies are recommended for field cultivation and commercialization in the developing countries where agriculture, urbanization, 
and industrialization are leaving a legacy of environmental degradation. Iran must formulate appropriate agricultural policies at a national level to enhance the extension services and educate farmers to reduce fertilizer application for sustainable development.

\section{Funding}

This research received no external funding.

\section{Acknowledgments}

This research has no acknowledgment.

\section{Conflicts of Interest}

The authors declare no conflict of interest.

\section{References}

1. Mishra, S.; Reddy-Noone, K.; Jain, A.; Verma, K. Monitoring organophosphorus pesticides and their degradation products formed by Fenton's reagent using solid-phase extraction-gas chromatography-mass spectrometry. Int. J. of Environment and Pollution 2006, 27, 49-63, https://doi.org/10.1504/IJEP.2006.010453.

2. CPCB. Water Quality Status of Yamuna River. Central Pollution Control Board, Ministry of Environment \& Forests, Assessment and Development of River Basin 2006, 1.

3. Kanaujia; Malik, D.; Gupta, V. Risk assessment of heavy metal pollution in middle stretch of river Ganga: an introspection. International Research Journal of Environmental Sciences 2017, 6, 62-71.

4. Adepoju-Bello, A.; Alabi, O.M. Heavy metals: A review. The Nig. J. Pharm 2005, 37, 41-45.

5. Kumar, R. Monitoring Heavy Metals Contamination in Yamuna River for its toxicity level in water, sediments and fish. IOSR Journal Of Environmental Science, Toxicology And Food Technology 2013, 5, 113-118, https://doi.org/10.9790/2402-055113118.

6. Kumar, R.; Tripathi, R.; Gupta, A. Seasonal Variation of heavy metal concentration in water of River Yamuna, Allahabad, Uttar Pradesh, India. International Journal of Current Microbiology and Applied Sciences 2014, 3, 945-949.

7. Sankhla, M.S.; Kumari, M.; Nandan, M.; Kumar, R.; Agrawal, P. Heavy Metals Contamination in Water and their Hazardous Effect on Human Health-A Review. International Journal of Current Microbiology and Applied Sciences 2016, 5, 759-766, http://dx.doi.org/10.20546/ijcmas.2016.510.082.

8. Parihar, K.; Singh Sankhla, M.; Kumar, R. Water Quality Status of Yamuna River and its Toxic Effects on Humans. 2019, 6, 597-601.

9. Singh Sankhla, M.; Kumar, R.; Prasad, L. Variation of Chromium Concentration in Yamuna River (Delhi) Water due to Change in Temperature and Humidity. Seybold Report 2020, 15, 293-299.

10. Verma, N.; Kumar, R.; Singh Sankhla, M.; Parihar, K. Green Filter Development: An Innovative Technique for Removal of Heavy Metals from Water. ARC Journal of Forensic Science 2020, 5, 7-12, http://dx.doi.org/10.20431/2456-0049.0501002.

11. Sankhla, M.S.; Kumar, R. Contaminant of Heavy Metals in Groundwater \& its Toxic Effects on Human Health \& Environment. Int. J. Environ Sci Nat Res. 2019, 18, https://doi.org/10.19080/IJESNR.2019.18.555996.

12. Sankhla, M.S.; Kumar, R.; Prasad, L. Distribution and Contamination Assessment of Potentially Harmful Element Chromium in Water. International Medico-Legal Reporter Journal 2019, 2.

13. Sankhla, M.S.; Kumar, R.; Prasad, L. Zinc Impurity in Drinking Water and Its Toxic Effect on Human Health. Indian Internet Journal of Forensic Medicine \& Toxicology. 2019, 17, 84-87, https://doi.org/10.5958/0974-4487.2019.00015.4.

14. Sankhla, M.S.; Kumar, R.; Shefali. New and Advanced Technologies in Aquaculture to Support Environmentally Sustainable Development. Microbial Biotechnology: Basic Research and Applications Springer 2020, 1, 249-263, https://doi.org/10.1007/978-981-15-2817-0_11.

15. Yadav, H.; Kumar, R.; Sankhla, M. S. Residues of Pesticides and Heavy Metals in Crops Resulting in Toxic Effects on Living Organism. Journal of Seybold Report 2020, 15, 1527-1541.

16. Sankhla, M.S.; Kumar, R.; Prasad, L. Distribution and Contamination Assessment of Potentially Harmful Element Chromium in Water. International Medico-Legal Reporter Journal 2019, 2. 
17. Sankhla, M. S.; Kumar, R.; Prasad, L. Zinc Impurity in Drinking Water and Its Toxic Effect on Human Health. Indian Internet Journal of Forensic Medicine \& Toxicology 2019, 17, 84-87, https://doi.org/10.5958/0974-4487.2019.00015.4. .

18. Sankhla, M. S.; Kumari, M.; Nandan, M.; Kumar, R.; Agrawal, P. Heavy metal contamination in soil and their toxic effect on human health: a review study. Int. J. All Res. Educ. Sci. Methods, 2016, 4, 13-19.

19. Sankhla, M. S.; Sharma, K.; Kumar, R. Heavy metal causing neurotoxicity in human health. International Journal of Innovative Research in Science. Engineering and Technology, 2017, 6, 5. DOI:10.15680/IJIRSET.2017.0605054

20. Pateriya, A.; Verma, R.K.; Sankhla, M.S.; Kumar, R. Heavy Metal Toxicity in Rice and its Effects on Human Health. Letters in applied NanoBioScience $\mathbf{2 0 2 0}, \quad 10, \quad$ 1833-1845, https://doi.org/10.33263/LIANBS101.18331845

21. Sonone, S.S.; Jadhav, S.; Sankhla, M.S.; Kumar, R. Water Contamination by Heavy Metals and their Toxic Effect on Aquaculture and Human Health through Food Chain. Letters in applied NanoBioScience 2020, 10, 2, 2148-2166.

22. Sankhla, M.S.; Kumar, R.; Biswas, A. Dynamic nature of heavy metal toxicity in water and sediments of Ayad River with climatic change. Int J Hydro. 2019, 3, 339-43, https://doi.org/10.15406/ijh.2019.03.00197. 